This item was submitted to Loughborough's Research Repository by the author.

Items in Figshare are protected by copyright, with all rights reserved, unless otherwise indicated.

\title{
Evaluation of the wind shear at a site in the North-West of the Yucatan Peninsula, Mexico
}

PLEASE CITE THE PUBLISHED VERSION

http://dx.doi.org/10.1260/0309-524X.33.1.93

PUBLISHER

(c) Multi-Science Publishing

VERSION

VoR (Version of Record)

LICENCE

CC BY-NC-ND 4.0

REPOSITORY RECORD

Soler-Bientz, Rolando, Simon J. Watson, and David Infield. 2019. "Evaluation of the Wind Shear at a Site in the North-west of the Yucatan Peninsula, Mexico". figshare. https://hdl.handle.net/2134/7341. 
This item was submitted to Loughborough's Institutional Repository (https://dspace.lboro.ac.uk/) by the author and is made available under the following Creative Commons Licence conditions.

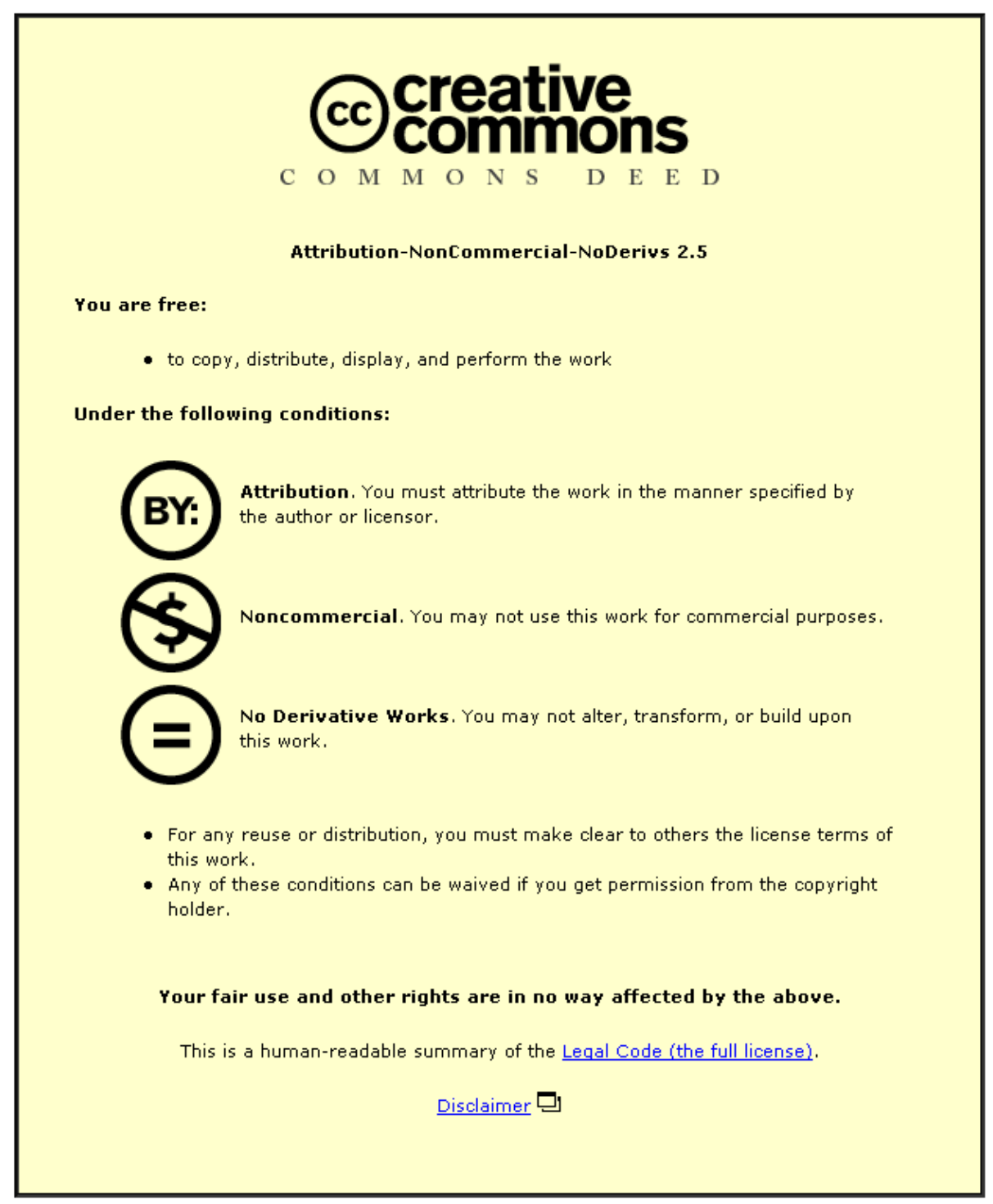

For the full text of this licence, please go to: http://creativecommons.org/licenses/by-nc-nd/2.5/ 


\title{
Evaluation of the Wind Shear at a Site in the North- West of the Yucatan Peninsula, Mexico
}

\author{
Rolando Soler-Bientz, ${ }^{1,2, *}$ Simon Watson' and David Infield ${ }^{3}$ \\ 'Centre for Renewable Energy Systems Technology (CREST), Department of Electronic \\ and Electrical Engineering, Loughborough University, United Kingdom \\ Tel: +44 I509 635338, Fax: +44 I509 63534I, E-mail: sbientz@msn.com \\ ${ }^{2}$ Energy Laboratory, Faculty of Engineering, Autonomous University of Yucatan, Mexico \\ ${ }^{3}$ Institute of Energy and Environment, University of Strathclyde, Glasgow, United Kingdom
}

\begin{abstract}
Extrapolations from $10 \mathrm{~m}$ above the ground up to the wind turbine hub height are frequently made to the data available for wind power assessments. Because of its simplicity, the power law profile has been one of the most popular mathematical formulations to predict the vertical wind shear. This paper presents an analysis of wind speed and wind shear in terms of the directional, diurnal and seasonal patterns for a site at the Autonomous University of Yucatan which experiences the tropical conditions of the Yucatan Peninsula in Mexico. This analysis takes a detailed look at frequency distributions to facilitate a comprehensive understanding of the local climatic conditions. Diurnal wind speed variations are shown to be affected in particular by the differing wind conditions associated with fetches over two distinct offshore regions. Seasonal behaviour suggests some departure from the oscillations expected from temperature variation. In addition, the use of rate of change of temperature at one height is proposed as an alternative to vertical temperature gradient inferred from two heights as an indicator of atmospheric stability which will affect the wind shear. The work presented is part of a regionally funded research program to evaluate the onshore and of fshore wind potential in the north of the Yucatan Peninsula.

Keywords: Wind shear, Wind direction, Frequency distribution, Diurnal variation, Atmospheric stability, Seasonal variation.
\end{abstract}

\section{INTRODUCTION}

The yield of a Wind Energy Conversion System (WECS) is highly dependent on the precision of the wind speeds used to compute the wind energy potential. In order to assess the wind potential for a wide area, it may not be feasible to install a large number of masts with measurements made at typical wind turbine hub heights (presently $60 \mathrm{~m}-80 \mathrm{~m}$ ). Wind speed data from existing meteorological stations are often used initially for this purpose. Usually wind speed data from meteorological stations are measured at $10 \mathrm{~m}$ above ground level (a.g.l.). The wind speed at the turbine hub height must then be determined from estimates of the site wind shear based upon locally available data. A number of papers have been published to address this subject depending, among other factors, on the amount and kind of meteorological data available, the geographical location (inland, onshore or offshore), the 
topography and the distribution of buildings around the study site (mainly for urban cases). When the atmospheric stability is neutral, the simple adiabatic log law is reasonably effective in predicting the wind profile, but for other stability conditions additional information is required to accurately estimate the wind shear according to Monin-Obukhov similarity theory $[1,2]$.

In the cases of offshore conditions, Van Wijk et al. [3] obtained good estimates for the seasonal mean wind speed in the North Sea after applying their "diabatic" method to calculate the wind speed profile as a function of height, when wind speed, sea water temperature and air temperature are known. This diabatic method was also used by Coelingh et al. to study offshore [4] and onshore sites [5]. These two studies of the North Sea and its coastal areas concluded that diurnal variations are very similar in autumn and winter and that the thermal circulation leads to sea breezes with important effects up to $30 \mathrm{~km}$ offshore for wind speeds lower than $7 \mathrm{~m} / \mathrm{s}$.

For the marine environment of the Danish Baltic Sea, Lange et al. [6] studied the influence of thermal effects on wind speed profiles computing the Obukhov length using three different methods. Their results showed that the standard Monin-Obukhov theory predicted lower wind speed values than measured for stable and near-neutral conditions, especially at large distances from the shore.

Using wind speed and air temperature data measured from one onshore site and two offshore towers, Pryor and Barthelmie [7] applied parameterization methods to compute the Monin-Obukhov length in a study of wind speed, stability and surface roughness. They reported that wind speed distributions onshore and offshore were statistically different for heights less than $20 \mathrm{~m}$ regardless of the atmosphere stability conditions, at distances less than $2 \mathrm{~km}$ from the shore. In an extended study using data from the Danish monitoring network [8], the same authors concluded that sites located within $2 \mathrm{~km}$ from the coastline could experience significant vertical shear and differing turbulence because the wind speeds close to the sea surface were frequently decoupled from the wind characteristics above $30 \mathrm{~m}$ in height.

Lapworth [9] reported diurnal patterns with maximum winds overnight and minimum values occurring during the afternoon for the offshore surface winds around the English coasts after applying numerical models for stable boundary layers to offshore measurements made in static vessels. On the other hand, Barthelmie et al. [10] studying the coastal meteorology of Denmark found that the offshore sites which receive winds from over the land showed a typical onshore pattern with lowest wind speeds overnight and highest wind speeds during the afternoon. Generally, the increase in offshore wind speeds overnight is produced by the lower roughness of the sea surface and the transition from stable conditions over land to less stable conditions over sea. During the day, the transition from unstable conditions over land to stable conditions offshore means that the surface layer becomes decoupled from higher wind speeds aloft and the wind speed close to the surface layer is lower, as was reported by Barthelmie et al. [11].

In the cases where not enough data is available to apply the Monin-Obukhov theory, the use of the power law to compute the wind shear exponent has been used as an alternative to predict the vertical profile. Farrugia [12] studied the wind shear from measurements at two different heights on Malta's South West coast, in the central Mediterranean, reporting that the monthly values decrease in summer and increase in winter and that the daily pattern has a period of a minimum from 9:00 to 15:00 and a period of a maximum from 21:00 to 5:00. Similar diurnal patterns were found by Rehmana and Al-Abbadib during 3 years [13] and 5 years [14] for a site in the coast of the Gulf region of Saudi Arabia. In this case, no regular seasonal trends were identified. 
Kirchhoff and Kaminsky [15] remarked that basic errors could be introduced because of the random nature of the wind speed and the deterministic characteristic of the power law when computing the wind shear from measured wind speeds at two different heights. Kirchhoff and Kaminsky made 173 wind speed measurements to study the wind shear so as to be statistically significant. Their data analysis indicated a normal distribution for the wind shear in three of the synoptic weather categories: I (in a warm section), III (behind a cold front) and IV (under a continental polar or arctic high).

The simplicity of the power law has made it perhaps the most widely applied model of wind shear. Nevertheless, atmospheric conditions and geographical characteristics of a particular region can create important variations in the wind shear patterns. This paper presents a comprehensive analysis of the wind speed and wind shear at a specific site in the Yucatan Peninsula in terms of the directional, diurnal and seasonal patterns. In particular the frequency distribution of the key parameters is examined to account for the diverse wind shear characteristics identified.

This research is focused on a region where the vertical behaviour of the wind has not been studied previously. This work is part of a regionally funded research program to evaluate the inland and offshore wind potential of the North of the Yucatan Peninsula.

\section{MEASUREMENT CONDITIONS}

\section{I. Geographical location}

The measurement site is located in eastern Mexico in the State of Yucatan close to the north coast of the Yucatan peninsula. This is therefore a tropical climate which should be strongly influenced by the proximity of the Caribbean Sea to the East and the Gulf of Mexico to the North and West. Figure 1(a) shows a map of North and Central America indicating with a black square the geographical position of the Yucatan peninsula. The measurement tower is installed at the Science and Engineering Campus of the Autonomous University of Yucatan which is shown in Figure 1(b) with a small star.

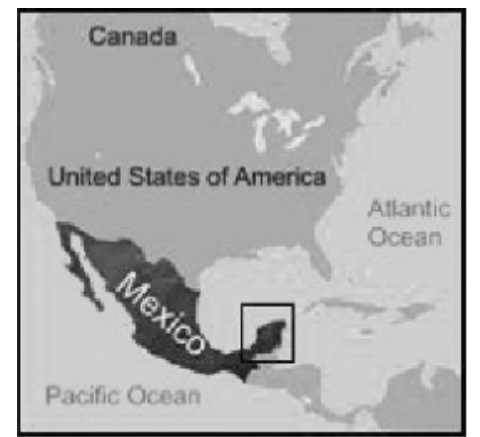

(a)

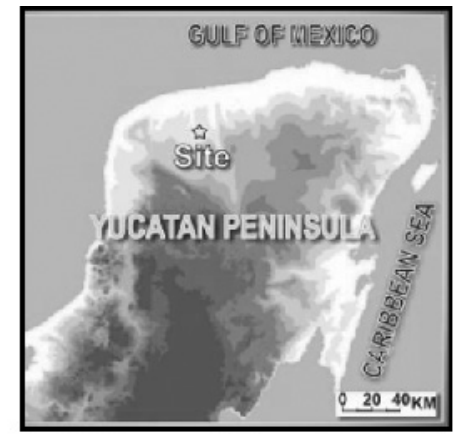

(b)

Figure 1: (a) Geographical location of the Yucatan peninsula in relation to the North American subcontinent. (b) The measurement site is shown in the North of the Yucatan peninsula with a small star.

Table I: Parameters for the geographical location of the measurement tower

\begin{tabular}{lll}
\hline Site parameters & Values & \\
Geographical coordinates & GPS GEO & $21^{\circ} 02^{\prime} 55.69^{\prime \prime} \mathrm{N}, 89^{\circ} 38^{\prime} 36.68^{\prime \prime} \mathrm{W}$ \\
& UTM WGS84-16 & $225262 \mathrm{E}, 2329831 \mathrm{~N}$ \\
Site height a.m.s.l. & $6.9 \mathrm{~m}$ \\
Distance from the near coast & $25.3 \mathrm{~km}$ (Northerly direction) \\
Measurement heights a.g.l. & $10 \mathrm{~m}$ and 30 m
\end{tabular}




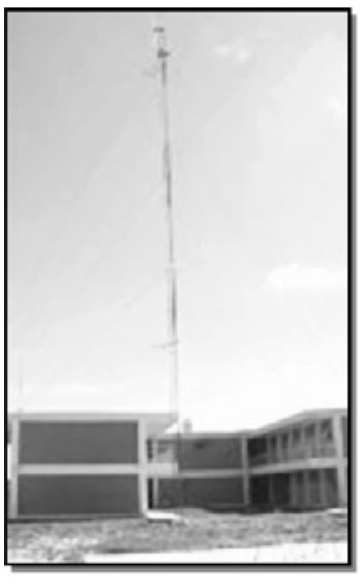

(a)

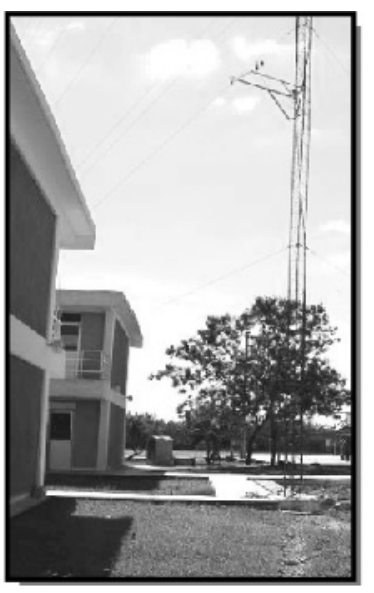

(b)

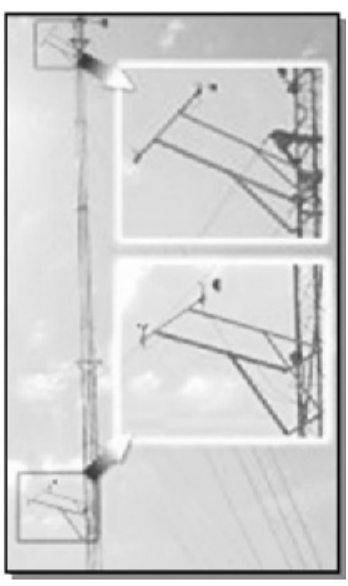

(c)

Figure 2: Images of the measurement tower: (a) overall view from the westerly direction, (b) view from the northerly direction showing the tower base, (c) close up view from the northerly direction showing the position of the installed sensors.

The topography of the North of the Yucatan Peninsula is mainly flat. Particularly, the measurement site which is located at around $25 \mathrm{~km}$ from the North shore is just about $7 \mathrm{~m}$ above the mean sea level (a.m.s.l.). Table 1 lists the main geographical parameters for the measurement site.

\subsection{Measurement sensors}

Figure 2(a) shows an overall view of the measurement tower. The nearest obstacle is located to the west of the tower at a distance of $5 \mathrm{~m}$ with a height of $7 \mathrm{~m}$; see Figure 2(b). In the right hand side image, Figure 2(c), a close up of the measurement tower is presented to identify the relative positions of the wind sensors at $10 \mathrm{~m}$ and $30 \mathrm{~m}$ height and at a distance of $1.5 \mathrm{~m}$ from the measurement tower. The wind sensors were installed facing the ENE direction because preliminary measurements shown that the westerly direction contributes less than $10 \%$ of the total winds at the site.

As well as two cup anemometers at $10 \mathrm{~m}$ and $30 \mathrm{~m}$ a.g.l. and a wind vane installed at $10 \mathrm{~m}$ a.g.l., a temperature sensor was also installed at $10 \mathrm{~m}$ a.g.l. The wind sensors were fully calibrated by the manufacturer and at the end of the study period this calibration was verified using a new ultrasonic wind sensor. The basic operational characteristics of the sensors are shown in Table 2.

\subsection{Main obstacles}

The behaviour of the wind speeds, especially at low heights, is affected by the surface characteristics. Thus, the immediate surroundings, as with all meteorological sites, are of

Table 2: Technical specifications of the sensors installed on the measurement tower

\begin{tabular}{lccc}
\hline & $\begin{array}{c}\text { Anemometer } \\
\text { RM Young 3101 }\end{array}$ & $\begin{array}{c}\text { Wind Vane } \\
\text { RM Young 3101 }\end{array}$ & $\begin{array}{c}\text { Temperature } \\
\text { Vaisala CS500 }\end{array}$ \\
Measurement range & 0 to $50 \mathrm{~m} / \mathrm{s}$ & $0^{\circ}$ to $360^{\circ}$ & $-40^{\circ} \mathrm{C}$ to $60^{\circ} \mathrm{C}$ \\
Resolution & $0.01 \mathrm{~m} / \mathrm{s}$ & $0.1^{\circ}$ & $0.01^{\circ} \mathrm{C}$ \\
System error & $1 \%$ & $\pm 5^{\circ}$ & $\pm 0.5^{\circ} \mathrm{C}$ \\
Starting threshold & $0.5 \mathrm{~m} / \mathrm{s}$ & $0.8 \mathrm{~m} / \mathrm{s}$ & N/A
\end{tabular}




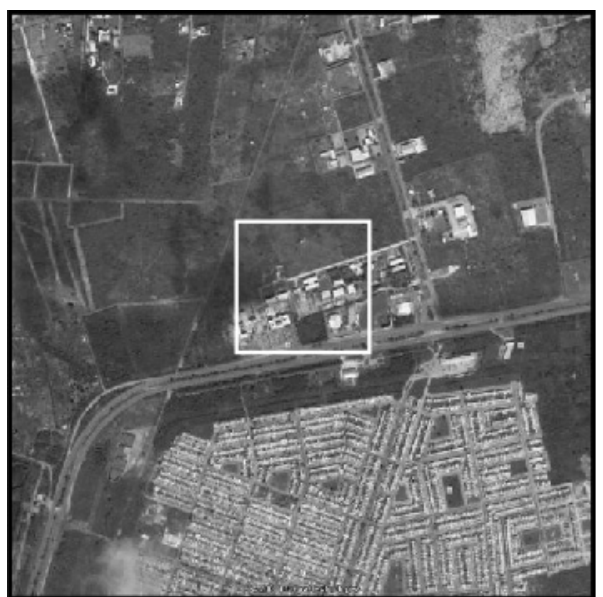

(a)

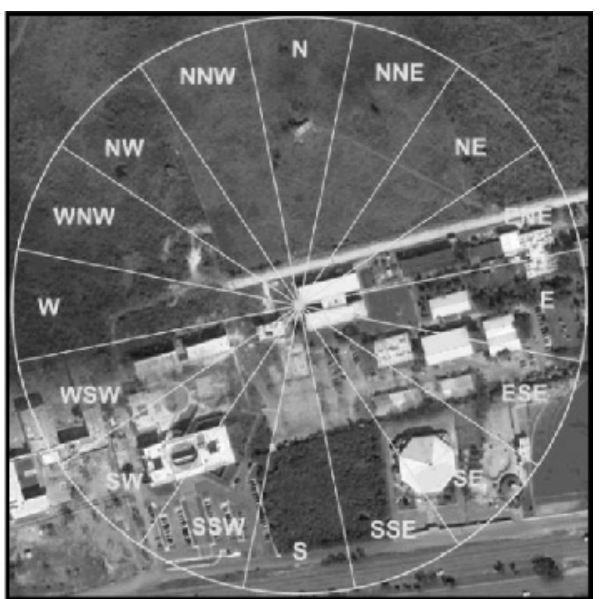

(b)

Figure 3: Satellite photos showing an aerial view of the measurement site. (a) A square area of $1600 \mathrm{~m}$ $\times 1600 \mathrm{~m}$ (b) a close up of the $400 \mathrm{~m} \times 400 \mathrm{~m}$ area with the directional sectors around the measurement tower.

importance because of their influence on the wind speeds and the wind shear in particular. Fig. 3(a) shows a satellite photo of approximately $1.6 \mathrm{~km}$ around the measurement tower. The closest region to the measurement point is marked with a square in the centre of Fig. 3(a) and it has been magnified in Fig. 3(b). This magnified area of approximately $400 \mathrm{~m} \times 400 \mathrm{~m}$ shows the closer obstacles that could influence the wind patterns across the site.

Sixteen directional sectors have been drawn in Fig. 3(b) to identify the angular position of the main obstacles relative to the measurement tower. Table 2 shows panoramic views of the main four main regions that surround the measurement tower. These regions were defined considering the position of the main group of obstacles and the results presented in the following sections. The photos show a view as seen from the sensors installed at $10 \mathrm{~m}$ a.g.l. on the measurement tower.

\section{WIND SHEAR}

Due to the number of obstacles close to the tower, we concentrate our analysis on the relative wind shear observed rather than absolute wind speed values. We assume that for the purposes of assessing wind energy potential at wind turbine hub height that, as mentioned in the introduction, the wind profile in the atmospheric surface layer is commonly described by the Monin-Obukhov similarity theory [1], which predicts an extended log-linear form shown in eq. (1). It describes the wind speed $\mathrm{u}$ at a particular height $\mathrm{z}$ as function of the friction velocity $\mathrm{u} *$, the roughness length $\mathrm{z}_{0}$ and the Obukhov length $\mathrm{L}$. In this equation $\mathrm{k}$ denotes the von Karman constant (typically taken as 0.4 ) and $\psi_{m}$ is the stability function.

$$
U(z)=\frac{U_{*}}{k}\left[\ln \left(\frac{z}{z_{0}}\right)-\psi_{m}\left(\frac{z}{L}\right)\right]
$$

Different models have been proposed to compute the parameters in the Eq. (1) which usually involve the measurement of the ambient temperature at two different heights.

In our case, temperature measurements are only available at one height. In addition Eq. (1) requires estimates of the surface roughness which are quite complex to infer with buildings in the immediate vicinity of the mast. We are interested mainly in the wind shear observed at the 


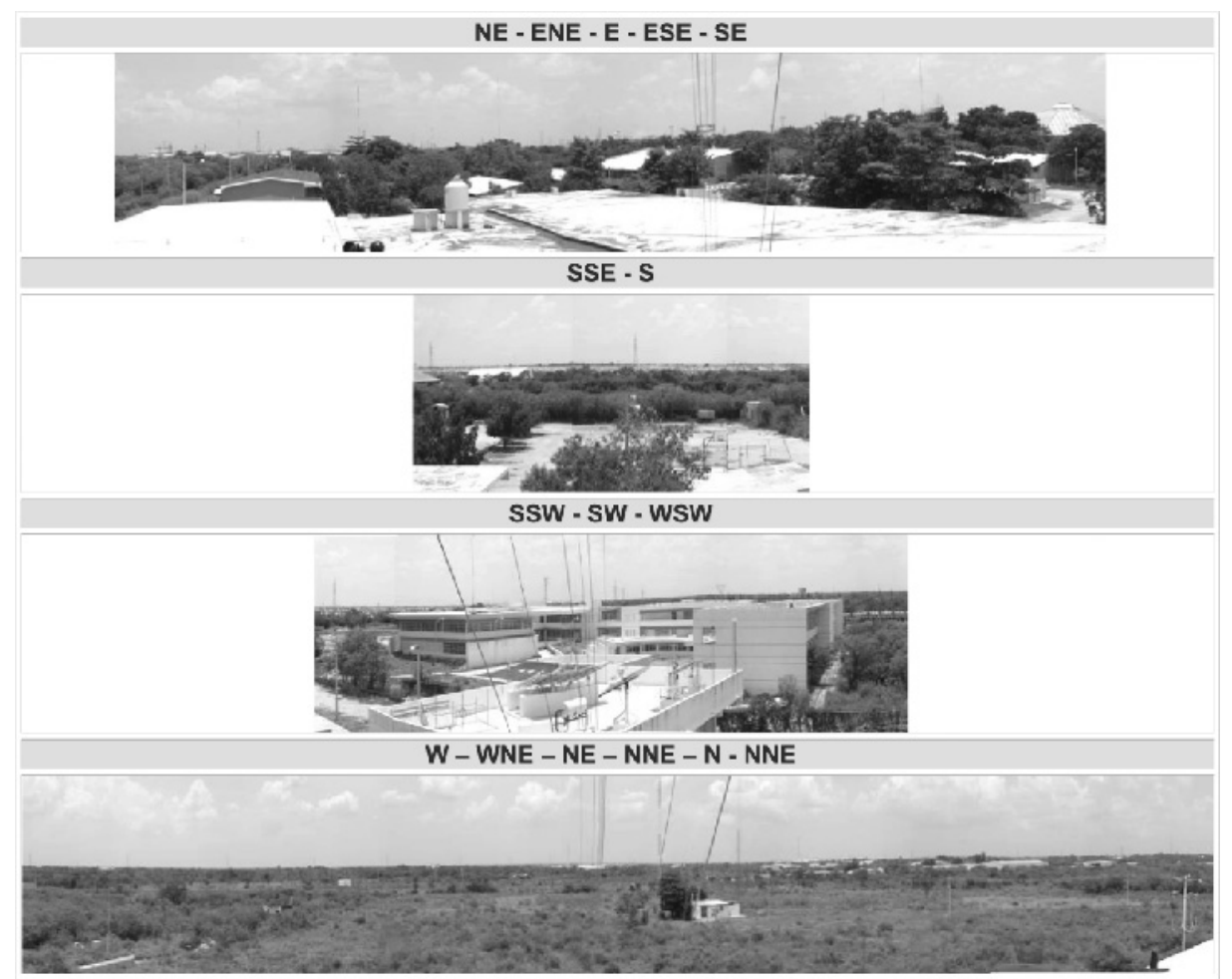

Figure 4: Panoramic views of the terrain surrounding around the measurement tower grouped in four main directions.

mast from the wind speeds measured at the two heights and thus use the empirical power law as given in Eq. (2):

$$
U(z)=U\left(z_{r}\right)\left(\frac{z}{z_{r}}\right)^{\alpha}
$$

where $\alpha$ represents the wind shear exponent which can be calculated, see eq. (3), when the wind speed values at two different heights, $\mathrm{U}(\mathrm{z})$ and $\mathrm{U}\left(\mathrm{z}_{\mathrm{r}}\right)$, are available:

$$
\alpha=\frac{\log \left(\frac{U(z)}{U\left(z_{r}\right)}\right)}{\log \left(\frac{z}{z_{r}}\right)}
$$

In the case presented in this paper $\mathrm{z}=30 \mathrm{~m}$ and $\mathrm{z}_{\mathrm{r}}=10 \mathrm{~m}$, thus eqn (3) can be expressed as:

$$
\alpha=2.0959 \cdot \log \left(\frac{U(30)}{U(10)}\right)
$$

\section{MEASUREMENT RESULTS}

The data used in this work comprise 64,451 records which were computed over 18 months of measurements since April 2003. These records contain the average every 10 minutes of the measurements sampled every 2 seconds from the installed sensors. The directional, diurnal and seasonal patterns were computed applying conventional averaging statistical methods 
(a)

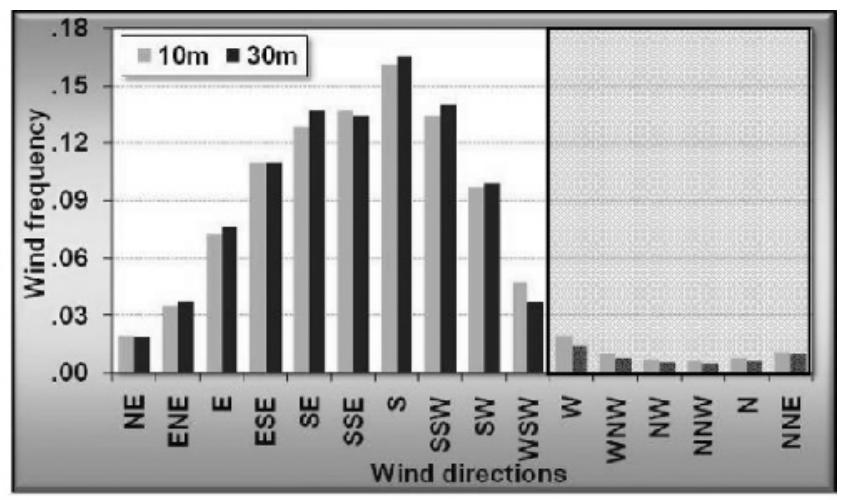

(b)

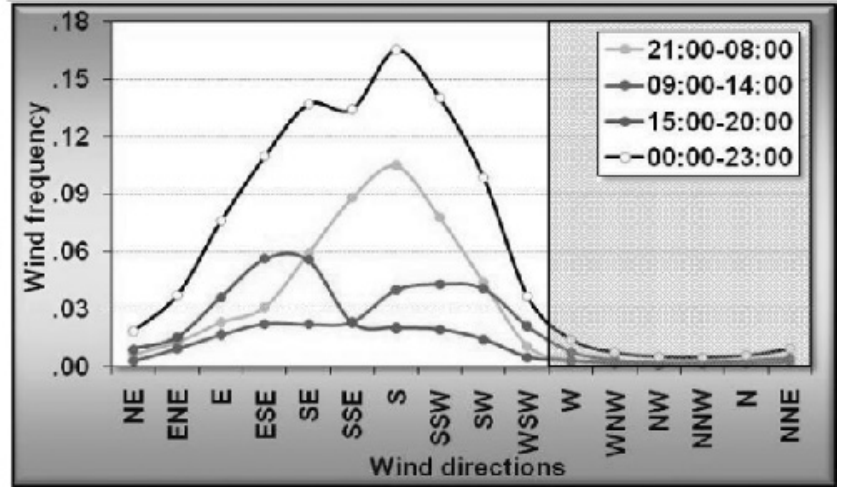

Figure 5: (a) Wind frequency distribution for each directional sector over the whole study period and (b) the contribution to the whole wind distribution of the three main diurnal periods.

from the 10 minute records. Frequency distribution patterns of wind speed and wind shear were also obtained classifying and processing the 10 minute records.

\section{I. Directional behaviour}

The distribution of the wind over 16 direction sectors is presented in Fig. 5(a) for all of the data available in the study period. The majority of the winds come from the sectors clustered around the South and less than the $8 \%$ of the winds come from the West to the North-East, which are shaded in Fig. 4(a). Therefore in the rest of the paper, we do not consider the directions from West to North-East.

In order to study the diurnal directionality of the wind at the site, the wind distribution for each hour was grouped in three time periods according the daytime/night-time and rate of change of temperature: 1) from 21:00 to 8:00 for predominantly night-time/negative rate of change of temperature, 2) from 9:00 to 14:00 for predominantly daytime/positive rate of change of temperature and 3) from 15:00 to 20:00 for predominantly daytime/negative rate of change of temperature. The resulting wind distributions for the three time periods have been plotted in Fig. 5(b) along with the wind distribution for the whole day (denoted 00:00 to 23:00). It can be seen that during the night, the wind comes over the land from around the South, during the morning, the contributions to the wind is greater from the South to the South-West while in the afternoon the contributions from the East to the South-East are greatest. This behaviour is fairly typical of a coastal site where the winds are thermally driven and a land-sea breeze develops during the day.

The wind speed average for each direction, see Fig. 6, shows that the highest wind speeds are located between the East and South-West direction sectors. As might be expected, the 


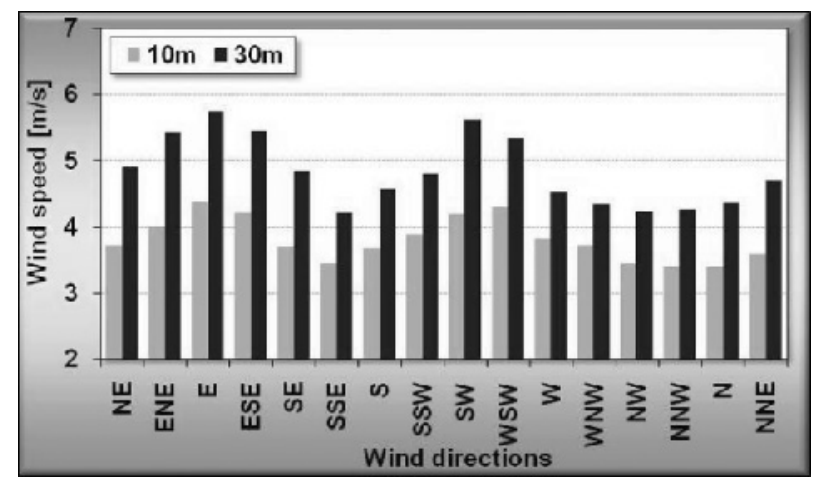

Figure 6: Wind speed averages over the whole study period for each direction sector.

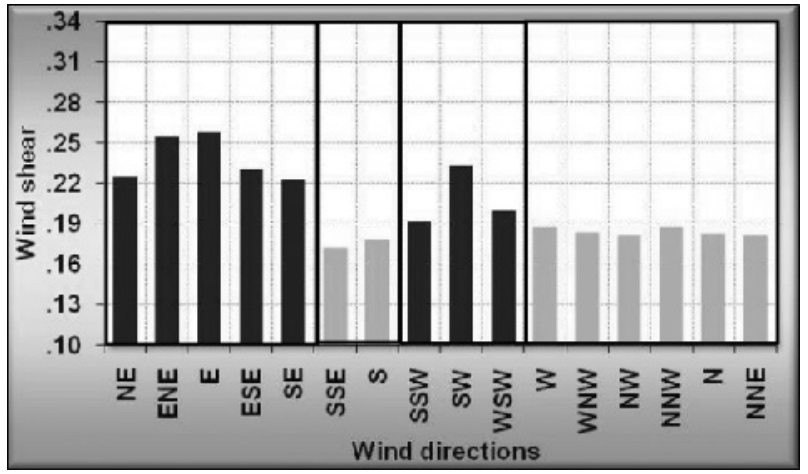

Figure 7: Wind shear averages over the whole study period for each direction sector.

largest differences in wind speed measured at $30 \mathrm{~m}$ and $10 \mathrm{~m}$ a.g.l. were also located in the directions with the highest wind speeds reflecting the effect of the buildings which tend to reduce the wind speed at $10 \mathrm{~m}$ a.g.l. but give some degree of acceleration at $30 \mathrm{~m}$ a.g.l. (see the location of the obstacles in Fig. 3(b) and Fig 4(a)).

Generally, the wind shear over a relatively flat surface with short vegetation can be computed by the one-seventh power law, i.e. $\alpha=0.14$ in Eq. (2). For the study site, as was expected because of the surroundings, the wind shear average computed over the whole study period was 0.21 varying between 0.17 and 0.26 over the different direction sectors as shown in Fig. 7. Notably, the largest and closest region of buildings located from the NE to the $\mathrm{SE}$ (NE-SE) gives rise to wind shear averages above 0.22 while the region with fewer and further obstacles from the SSW to the WSW (SSW-WSW) gives rise to wind shear averages above 0.19 . There is a small region, from the SSE to the S (SSE-S), and a larger region, from the WSW to the NNE, giving wind shear averages under 0.19 corresponding with regions where there are no obstacles close enough to the measurement tower to have an appreciable effect, as can be in Fig. 3(b) and Fig. 4. The wind shear averages in Fig 7 are not significantly influenced by the obstacles with average heights under $10 \mathrm{~m}$ located further than $300 \mathrm{~m}$ away (ten times the height of the measurement tower), namely: the large region of buildings to the South and another group of buildings located to the North, see Fig. 3(a) and Fig. 4. The main influence on the wind shear comes from the closer obstacles.

Frequently in the literature [10-13], an average based analysis is used to evaluate the wind shear patterns but, as was reported by Kirchhoff and Kaminsky [15], basic errors could be obtained as result of the deterministic property of the wind shear computed from the 


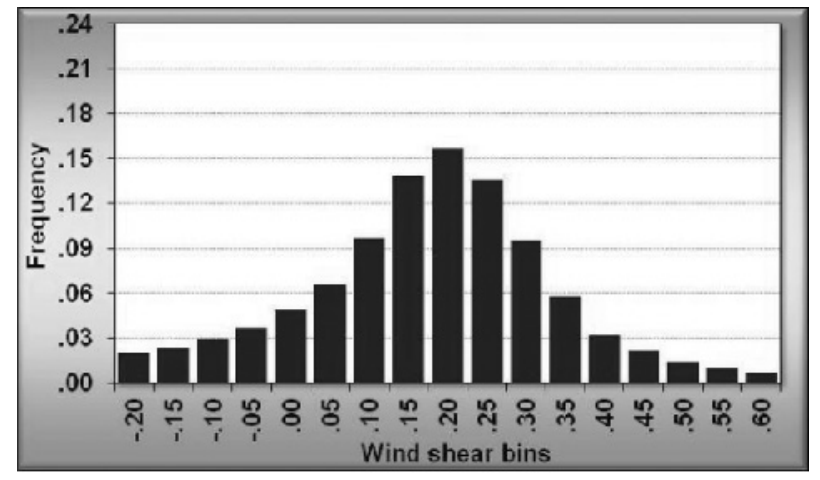

Figure 8: Frequency distribution of the wind shears over all directions.

power law. On the other hand, different stability conditions could be present in the atmosphere over the study period introducing unexpected values of wind shear. Thus, as the stability of the atmosphere cannot be derived from the data available in this research, the frequency distribution of the wind shear was computed to shed further light on the range of wind shear values.

The frequency distribution of the wind shear was computed from the 10 minutes data and grouped by bins of size 0.05 . Fig. 8 presents the frequency of the wind shear over all the directional sectors. As can be seen the wind shear values are distributed between -0.2 and 0.6 with a peak at 0.2 which is consistent with the average value of 0.21 previously computed. However, it is noticeable that there is a significant range of wind shear values observed which cannot be explained by differing roughness conditions by direction. Clearly, the effect of atmospheric stability is significant.

\subsection{Diurnal behaviour}

The diurnal wind speed behaviour is shown in Fig. 9(a). Three particular features are notable: a period of reduced wind speed at night, an abrupt increase in the wind speed early in the morning followed by fairly constant wind speeds during the early afternoon and finally a peak in the wind speed during the late afternoon/early evening. In general terms, this diurnal pattern is consistent with results for other coastal regions, e.g. by Barthelmie et al. [11] in the marine environment of Denmark, by Farrugia [12] for Malta and by Rehmana and Al-Abbadib $[13,14]$ in the Gulf region of Saudi Arabia.

In addition, the hourly average wind direction, shown above in Fig. 9(b), was divided into two periods: from 23:00 to 13:00 with averages in the S sector and from 14:00-22:00 with average directions in the SE and SSE sectors. For both of these periods the wind is blowing from the landward directions; see Fig. 1(b), which is not enough to explain the daily pattern shown by the wind speeds in Fig. 9(a). To give more information, the distribution of the wind in each direction for the diurnal periods was computed, see Fig. 10 below. The higher concentration of winds during the time period (21:00-8:00) came from the SE to the SW sectors, which is the land area of the Yucatan Peninsula. Then, during the time period (9:00-14:00) when the sun was rising, a larger fraction of the winds were coming from the SSW to the NNW sectors, which is direction of the West of the Gulf of Mexico. Finally, during the time period (15:00-20:00) when the sun is setting, the winds were clearly concentrated in the NNW to the SE sectors in the direction of the North-East of the Gulf of Mexico and the East of the Caribbean Sea, see maps in Fig. 1. 
(a)

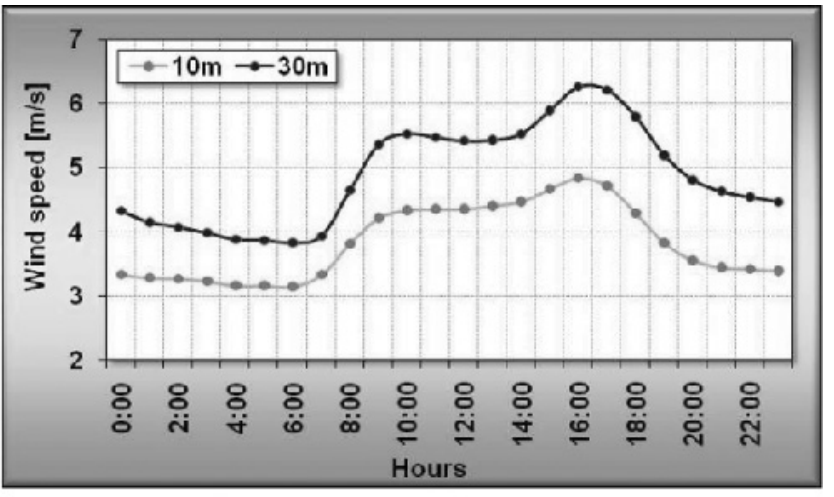

(b)

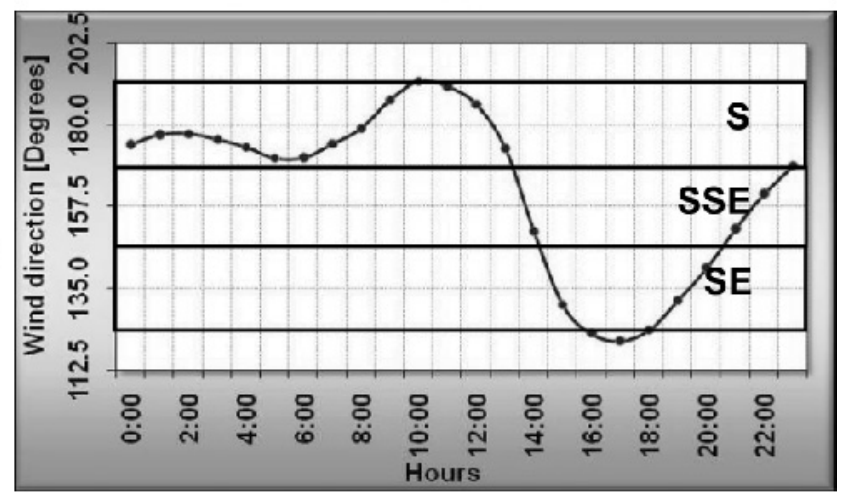

Figure 9: (a) Hourly wind speed averages and (b) hourly wind direction averages, computed for the whole study period.

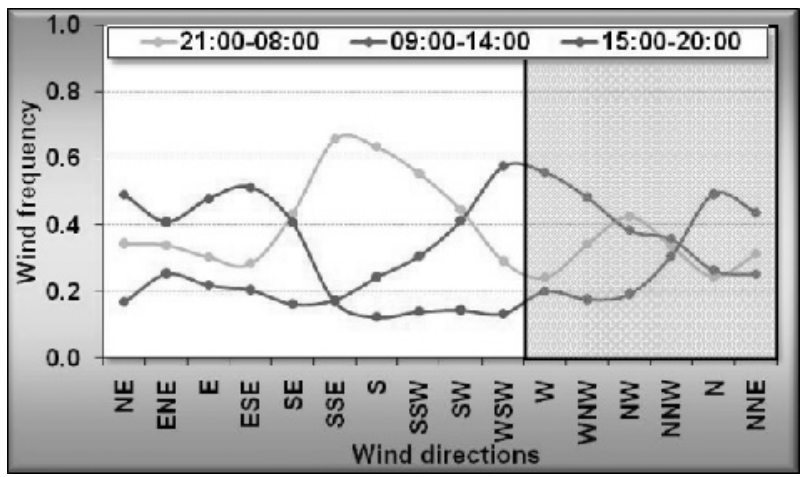

Figure 10: Distribution of the wind by directions, for the three main diurnal time periods. The shadowed region marks the directional sectors with less than $1.5 \%$ of wind over the whole study period, see distributions in Fig.5.

In summary, the wind speed patterns in Fig. 9(a) show wind mainly coming from the sea during the daytime and from the land during the night time. This is the standard pattern observed for sites close to the coast where the climate is determined not only by vertical thermal convection [16] but also by the horizontal movement produced by thermal circulation of the sea breeze $[4,17]$. However, in this case, a particular characteristic is seen for the daytime which shows two different sea regions driving the winds in different daylight periods and with different wind speed magnitudes.

The diurnal pattern of the wind shear along with the ambient temperature averages are shown in Fig. 11. The resulting pattern can be explained by means of the wind shear averages for each direction presented in Fig. 7 and the distribution of winds for the three main diurnal time periods from Fig. 10, excluding the low frequency region (W-NNE). During 


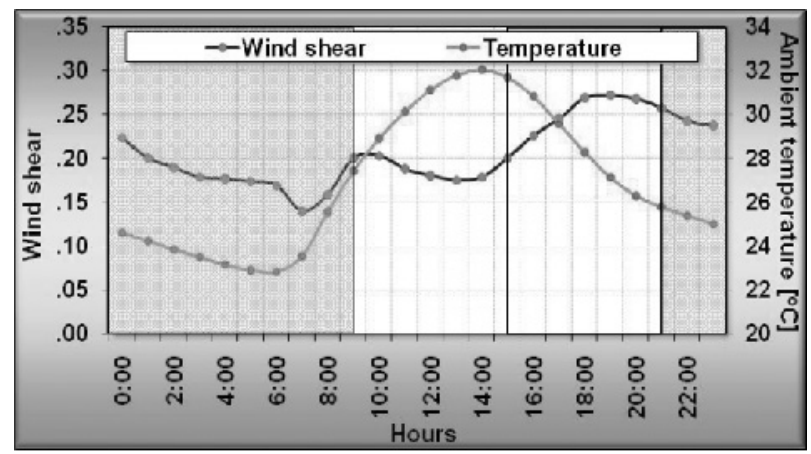

Figure 11: Diurnal patterns of the three main directional regions for the wind distribution (a) and the overall wind shear and ambient temperature averages for diurnal period (b).

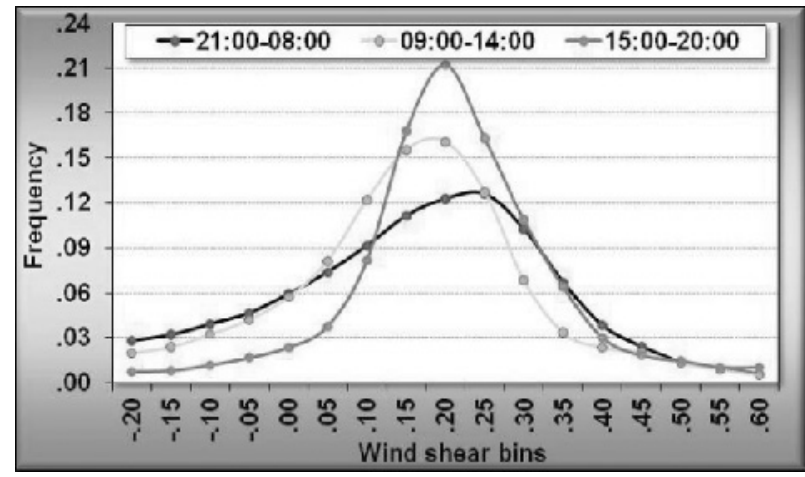

Figure 12: Frequency distribution of the wind shear for the three main diurnal periods.

the night time (21:00-8:00) the wind comes mainly from the SSE-S with lower wind shear averages, whereas during the morning (9:00-14:00) the main wind from the SSW-WSW gives rise to an increase in the wind shear averages and finally during the afternoon (15:00-20:00) the wind from the NE-SE dominates with the highest wind shear averages. The wind shear observed in these cases results from the combined effect of the location of the main obstacles; see Fig. 3(b), and from the thermal effects over the land and the sea around the measurement site.

Figure 12 below shows the frequency distribution of the wind shear over the whole study period classified by the three main diurnal time periods. It can be seen that the night time (21:00-8:00) period gives the greatest spread of values indicating a larger range of stability conditions. In contrast, during the daytime (9:00-14:00 and 15:00-20:00) the distribution is more centred around 0.20 which could indicate stability values closer to neutral.

\subsection{Thermal effects}

At this site, temperature measurements were only available at one height so it was not possible to calculate the Obukhov length $\mathrm{L}$ in Eq. (1) to determine whether the change in the observed wind shear was consistent with that seen from the wind speed measurements. As an alternative, the rate of change of temperature at one height was use as a proxy for the stability. The data in Figure 10 were used to plot the wind shear as a function of rate of change of temperature. These results are shown in Figure 13.

It can be seen from Fig. 13 that there is a clear trend whereby the wind shear decreases as the rate of change of temperature increases, though clearly there is some degree of scatter in 


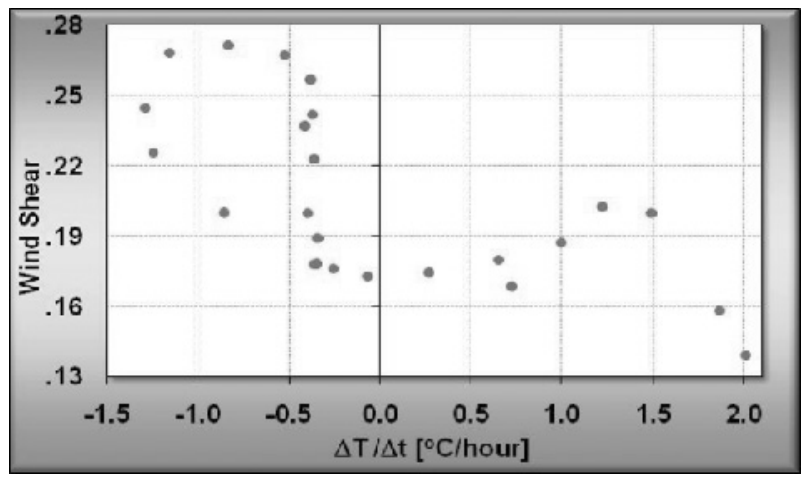

Figure 13: Wind shear as a function of rate of change of temperature.

the data. Negative values represent cooling which lead to stable conditions. This inhibits vertical mixing and leads to an increase in wind shear as expected. Positive values relate to heating and convection from the ground leading to unstable conditions. This increases mixing and reduces wind shear which is again what we would expect. In addition, the sensitivity of the wind shear to stable conditions is greater than that for instable conditions. This is consistent with the Businger-Dyer relations [18,19] which, when integrated, give the diabatic term $\psi_{m}$ in Eq. (1). The authors are not aware of any existing research which has done a similar analysis and this needs further data for investigation, but it is proposed that for a climate where strong diurnal heating and cooling is observed, that rate of change of temperature may be used as a proxy for vertical temperature gradient to infer atmospheric stability.

(a)

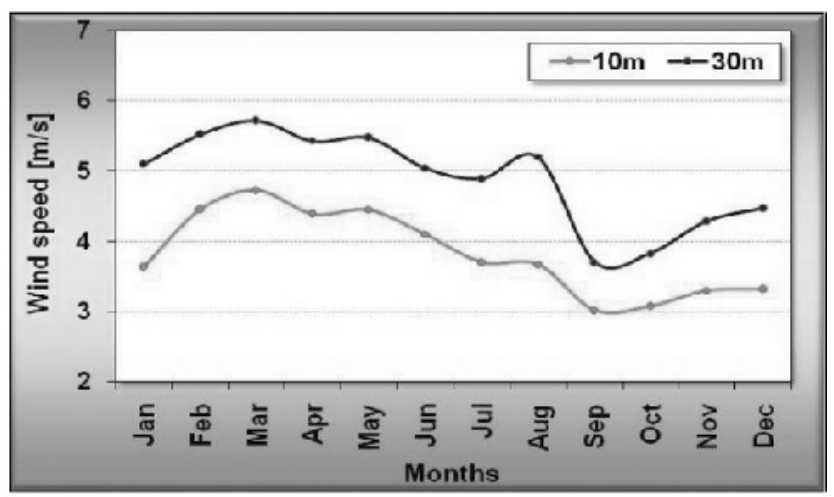

(b)

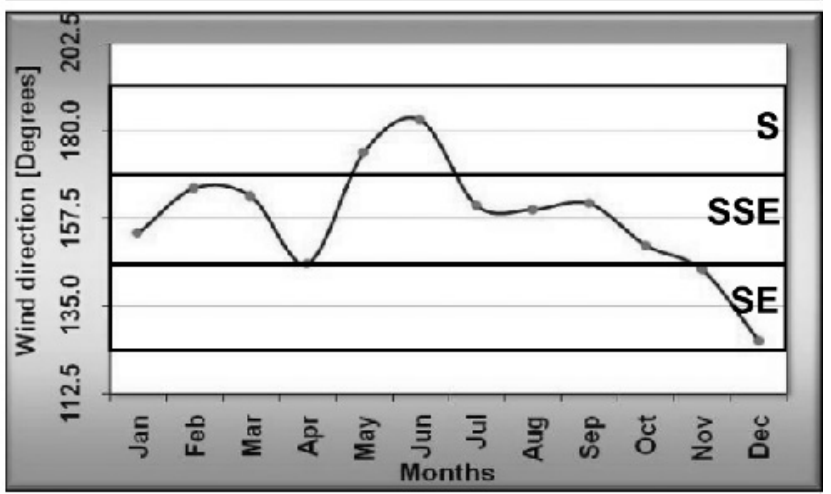

Figure 14: (a) Monthly wind speed averages and (b) monthly wind direction averages computed for the whole study period. 


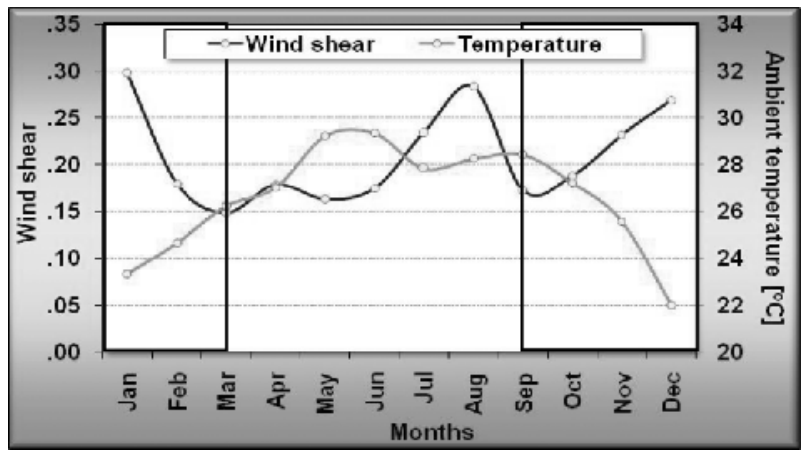

Figure 15: Combined plot of the monthly averages for the wind shear (left axis) and the averages of the seasonal ambient temperature (right axis).

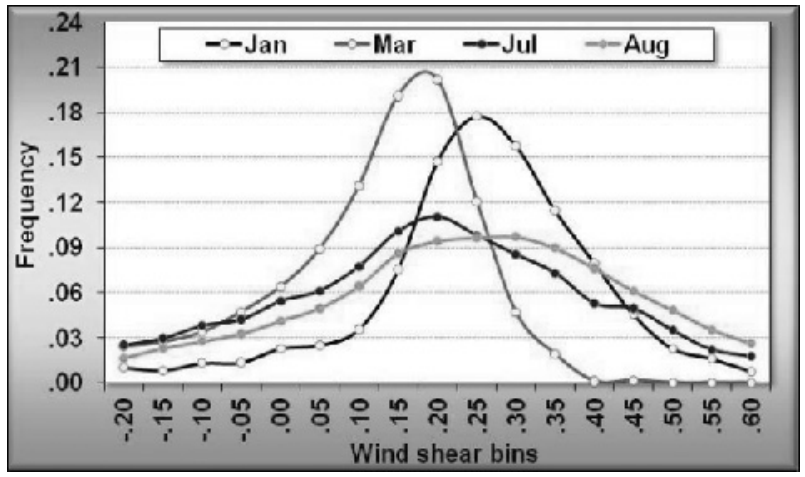

Figure 16: Wind shear frequency distributions for the months January, March, July and August.

\subsection{Seasonal behaviour}

The seasonal pattern of the wind speed can be seen in Fig. 14(a) showing that the wind reaches its maximum in March and its minimum in September. Fig. 14(b) shows that the monthly wind direction averages are close to the SSE for much of the year except for May and June when the wind comes more from the South and during December when the wind comes more from the SE.

Figure 15 below shows the annual temperature pattern which has a double peak produced by a decrease in the ambient temperature during the rainy season in June, July and August. The wind shear shows an increase in the winter months which is consistent with cooler stable conditions and is lower in the summer when warmer convective conditions dominate. The exception to this is during the rainy season, particularly during July and August.

During this period, an abrupt increase in the wind shears is seen. To shed further light on this, the frequency distribution of the wind shear for these two months and for the months where the minimum (March) and maximum (January) wind shear value are observed, is shown in Fig. 16. The January and March distributions are fairly peaked while the distributions for July and August are more widely spread. It is clear that during the rainy season, a wider range of climatic conditions is observed and is it is likely that the cloudier conditions are inhibiting ground heating and convection thus increasing the observed wind shear.

\section{CONCLUSIONS}

Wind speed and wind shear patterns have been studied for a site at the Autonomous University of Yucatan which experiences the tropical conditions of the north Yucatan Peninsula of western Mexico. 
Simple averaged values were found to be inadequate in describing the wind shear characteristics at the site in question. An analysis based on direction and frequency distribution proved to be more effective in describing the vertical wind profile.

Night time diurnal wind speed variations were identified with characteristics as expected for near coastal sites with lowest wind speeds blowing from land to sea. In contrast, during daytime, the higher winds coming from over the sea exhibit particular characteristics that reflect the two rather distinct fetches of offshore sea. At sunrise the wind tends to come from the west part of the Gulf of Mexico while towards sunset, the highest wind speeds come from the north-east of the Gulf of Mexico and the east of the Caribbean Sea where sea temperatures are rather different.

An analysis of the rate of change of temperature showed a correlation between wind speed and rate of change of temperature reflecting stable conditions during periods of cooling and unstable conditions during periods of heating. Though more data would be required to investigate this further, it is proposed that rate of change of temperature may be used as a proxy for vertical temperature gradient to infer atmospheric stability when temperature measurements are only available at one height, particularly where winds are dominated by thermal conditions.

The seasonal characteristics of the wind shear appear to be mainly driven by the temperature changes with some anomalous values during the rainy season which reflect cooler conditions and lower levels of convection.

In summary, the study illustrates that a complex coastal environment, as provided by the proximity of both the Gulf of Mexico and Caribbean Sea with their different sea conditions, can result in unusual wind characteristics, and in particular, non-standard diurnal wind variations and shear profiles.

\section{ACKNOWLEDGEMENTS}

The authors would like to recognise the commitment of the Energy Laboratory team at the Autonomous University of Yucatan who have maintained the measurement system throughout the study period. Special thanks to Mario Diaz Ocheita for the initial data collection and image processing. This work was developed as part of the research projects "FING-03-009" and "FING-05-016" at the Faculty of Engineering of the Autonomous University of Yucatan in collaboration with the Centre for Renewable Energy Systems Technology at Loughborough University and the Institute of Energy and Environment at University of Strathclyde.

\section{REFERENCES}

[1] Monin, A.S. and Obukhov, A.M., Basic laws of turbulent mixing in the surface layer of the atmosphere. Tr. Geofiz. Inst. Akad. Nauk SSSR, 1954, 151, 163-187.

[2] Foken T., 50 Years of the Monin-Obukhov similarity theory, Boundary-Layer Meteorology, 2006, 119, 431-447.

[3] Van Wijk, A.J.M., Beljaars, A.C.M., Holtslag, A.A.M. and Turkenburg, W.C., Evaluation of stability corrections in wind speed profiles over the North Sea, Journal of Wind Engineering and Industrial Aerodynamics, 1990, 33, 551-566.

[4] Coelingh, J.P., Van Wijk, A.J.M. and Holtslag, A.A.M., Analysis of wind speed observations over the North Sea, Journal of Wind Engineering and Industrial Aerodynamics, 1996, 61(1), 51-69. 
[5] Coelingh, J.P., Van Wijk, A.J.M. and Holtslag, A.A.M., Analysis of wind speed observations on the North Sea coast, Journal of Wind Engineering and Industrial Aerodynamics, 1998, 73(2), 125-144.

[6] Lange, B., Larsen, S., Højstrup, J. and Barthelmie, R.J., The influence of thermal effects on the wind speed profile of the coastal marine boundary layer, Boundary Layer Meteorology, 2004, 112, 587-617.

[7] Pryor, S.C. and Barthelmie, R.J., Analysis of the effect of the coastal discontinuity on near-surface flow, Ann. Geophys, 1998, 16, 882-888.

[8] Pryor, S.C. and Barthelmie, R.J., Statistical analysis of flow characteristics in the coastal zone, Journal of Wind Engineering and Industrial Aerodynamics, 2002, 90(3), 201-222.

[9] Lapworth, A., The diurnal variation of the marine surface wind in an offshore flow, Quarterly Journal of the Royal Meteorological Society, 2005,131(610), Part B, 2367-2387.

[10] Barthelmie, R.J., Courtney, M.S., Højstrup, J. and Larsen, S.E., Meteorological aspects of offshore wind energy: observations from the Vindeby wind farm, Journal of Wind Engineering and Industrial Aerodynamics, 1996, 62, 191-221.

[11] Barthelmie, R.J., Grisogono, B. and Pryor, S.C., Observations and simulations of diurnal cycles of near-surface wind speeds over land and sea, Journal of Geophysical Research, 1996, 101(D16), 21327-21337.

[12] Farrugia, R.N., The wind shear exponent in a Mediterranean island climate, Renewable Energy, 2003, 28(4), 647-653.

[13] Rehman, S. and Al-Abbadi, N.M., Wind shear coefficients and their effect on energy production, Energy Conversion and Management, 2005, 46(15-16), 2578-2591.

[14] Rehmana, S. and Al-Abbadib, N.M., Wind shear coefficients and energy yield for Dhahran, Saudi Arabia, Renewable Energy, 2007, 32, 738-749.

[15] Kirchhoff, R.H. and Kaminsky, F.C., Wind shear measurements and synoptic weather categories for siting large wind turbines, Journal of Wind Engineering and Industrial Aerodynamics, 1983, 15(1-3), 287-297.

[16] Holtslag, A.A.M., Estimation of diabatic wind speed profile from near-surface weather observations, Boundary Layer Meteorology, 1984, 29, 225-250.

[17] Van Delden, A., Observational evidence of the wake-like character of the sea breeze effect, Beilr. Phys, Atmosph, 1993, 66(12), 63-72.

[18] Businger, J.A., A note of the Businger-Dyer profiles, Boundary Layer Meteorology, 1988, 42, 145-151.

[19] Panofsky, H.A. and Dutton J.A., Atmospheric Turbulence, Wiley Interscience, New York, 1984, 397. 
